\title{
Avanços e desafios de inclusão na perspectiva linguística da educação escolar indígena
}

\section{Advances and challenges of inclusioan in the linguistic perspective of indigenous school education}

\author{
Greicy Oliveira Nascimento, Luciane Rocha Paes \\ Universidade Federal do Amazonas
}

\begin{abstract}
Resumo
Este trabalho surgiu a partir de uma experiência de campo através de um projeto de extensão pela Universidade Federal do Amazonas - IEAA, na Escola Municipal Indígena São José. A metodologia utilizada para a realização desde trabalho foi de cunho qualitativo e bibliográfico, no qual contou-se com os dados da observação de um projeto de campo aplicado na Aldeia Pupunha do povo Parintintim. A Educação Escolar Indígena tem contribuído para o processo de ensino e aprendizagem nas comunidades indígenas, reafirmando a identidade indígena, em seus direitos e significados da posse da terra, na manutenção e no resgate da cultura, tradições, saberes e entre outros reafirmando os valores sociolinguísticos que estão presentes na cultura indígena como um todo.

Palabras-chave: cultura, educação indígena, inclusão, linguagem.
\end{abstract}

\begin{abstract}
This work arose from a field experience through an extension project by the Federal University of Amazonas IEAA, in the Municipal School of São José Indígena. The methodology used since the work was qualitative and bibliographic, With the observation data of a field project applied in the Village Pupunha of the Parintintim people. Indigenous School Education has contributed to the process of teaching and learning in indigenous communities, reaffirming indigenous identity in their rights and meanings of land tenure, in the maintenance and recovery of culture, traditions, knowledge and among others reaffirming sociolinguistic values Which are present in the indigenous culture as a whole.

keywords: Culture, indigenous education, language.
\end{abstract}

\section{Introdução}

Este artigo relata a experiencia de campo no território indígena da etnia Parintintin onde também há indígenas da etnia Torá, na aldeia da Pupunha que está localizada na BR 330, a 7 km do município de Humaitá-AM. Diante de uma visita que tinha como objetivo observar e levantar informações a respeito da educação escolar dessa aldeia para um projeto de extensão da Universidade Federal do Amazonas foi observado que os indígena não possuíam o domínio da língua materna, apenas o Cacique Antônio Parintintin e sua esposa
Claudete Parintintin falam a língua Tupi-Guarani em meio a cerca de 150 indígenas que compõem a aldeia.

A língua foi um dos primeiros trunfos utilizados pelos não-índios no início da colonização, através dela foi que se tornou possível o contato "dialogado" com os indígenas. Causas e consequências deste o primeiro contato estão presentes até os dias atuais em diversas etnias espalhadas pelo Brasil, muitos indígenas estão "destribalizados" sem característica e identidade indígena, e perderam totalmente sua língua materna como resalta Silva (1994 p. 45) "são muito numerosos os povos que, por força da violência exercida no passado pelas agências da sociedade brasileira, não tiveram outra alternativa senão o abandono de suas línguas tradicionais". Afonso (2014) afirma que todas estas ações foram e estão ligadas a intenção de fazer com que os indígenas deixassem de ser "primitivos" e se tornassem cidadãos "civilizados", falantes da língua portuguesa compondo assim, uma nova identidade.

As comunidades indígenas estão tendo um maior amparo legal na área educacional e na preservação da sua cultura. Através desse contexto, podemos perceber uma preocupação em preservar a identidade e a culturas dessas comunidades. E fazendo com que o ensino promova a inclusão social e cultural, Pois a Educação Escolar Indígena tem contribuído para o processo ensino/aprendizagem nas escolas que por sua vez tem favorecido na (re) afirmação da identidade indígena, nos direitos e significados da posse da terra, na manutenção/resgate da cultura, tradições, saberes e entre outros. A legislação garante os direitos do povo indígena, inclusive a uma educação diferenciada capaz de fortalecer a afirmação étnica e cultural. Com o intuito de preservação da realidade da comunidades.

\section{Avanços e desafíos enfrentados pela educação Escolar Indígena}

A educação escolar indígena é o campo de política pública voltada para os povos indígenas que mais avançou no país, porém alguns problemas ainda persistem. Mas é grande o esforço, e só através de toda essa luta é que hoje em dia houve as conquistas 
alcançadas, resultado de muitas lutas e esforços de professores e lideranças indígenas, assim como, de muitos técnicos, gestores e dirigentes do poder público. Podemos ver que esse processo histórico foi marcado por conflito, resistências, derrotas e vitórias, e assim levou a criação de um conjunto de leis, normas, e regras jurídicas que tinha como objetivo orientar as relações entre os povos indígenas e as comunidades envolventes. Podemos ver na Lei de Diretrizes e Bases da Educação (LDB) um conjunto de orientações que proporcionam um avanço significativo nas políticas públicas no que diz respeito à Educação Escolar dos Povos Indígenas. Senão vejamos o que reza a Constituição Federal já no Capítulo VII em seu Artigo 231:

São reconhecidos aos índios sua organização social, costumes, línguas, crenças e tradições, e os direitos originários sobre as terras que tradicionalmente ocupam, competindo à União demarcá-las, proteger e fazer respeitar todos os seus bens (Constituição da República, 1988).

Como se pode constatar é reconhecido e legitimado que os povos indígenas tenham reconhecidos seus direitos básicos de acesso a educação e, com o respeito e acolhimento de suas tradições, crenças e formas de viabilizar sua existência. Mas, podemos notar que um dos maiores desafios da escola indígena na atualidade está no campo pedagógico, ou seja, como pôr em prática, os conceitos político-pedagógicos inovadores da educação escolar indígena, pois nem sempre o que está no papel é feito, e assim existe um certo tipo de exclusão, pois na maioria das vezes o sistemas de ensino resistem as mudanças.

A resistência é resultado de um misto de medo ou insegurança dos gestores diante do novo, do diferente, do imprevisível e de um comodismo ou apego aos antigos modelos e padrões de escola e de educação escolar tradicional colonial. E além do mais, na maioria das vezes os sistemas de ensino não possuem estruturas adequadas e equipes qualificadas para atender as demandas das escolas indígenas, resultando na baixa capacidade e qualidade na execução dos programas de construção de escolas, elaboração de material didático, transporte escolar, alimentação escolar e a formação de professores que hoje em dia é bem comentada pela sua total importância para o estudo.

Dessa forma, para o Referencial para a formação de professores indígenas (2002, p.20):

Pode-se dizer que os professores indígenas são os mediadores, por excelência, das relações sociais que se estabelecem dentro e fora da aldeia, por meio também da escola. Assim, eles ou elas têm uma função social distinta dos professores não-índios, pois assumem, muitas vezes, o papel de intérpretes entre culturas e sociedades distintas.

E assim vemos que são muitos os desafios enfrentados pelas escolas indígenas, e a transformação ou mesmo uma nova criação de novas experiências pedagógicas de ensino-aprendizagem nas escolas indígenas, na perspectiva de uma escola e uma educação intercultural, bilíngüe, específica, diferenciada e própria com tempo, espaço, conteúdo curricular, metodologias, pedagogias, didáticas e epistemologias próprias dependem da capacidade de gestão das comunidades e do movimento indígena organizado, todo esse sistema sonha em construir uma escola indígena que vá além da cultura critica, ela deseja abrir novos espaços para outros modos de transmissão de conhecimentos por meio da oralidade, da imagem, da observação e repetição de bons exemplos dos mais velhos e do aprender fazendo, vivendo, experimentando, pesquisando e descobrindo. Como ressalta Maturana (2002, p.13)

A tarefa da educação escolar é permitir e facilitar o crescimento das crianças como seres humanos que respeitem a si próprios e os outros com consciência social e ecológica, de modo que possam atuar com responsabilidade e liberdade na comunidade a que pertencem.

A formação dos professores indígenas corresponde a um dos mais importantes pontos da política pública no que respeita à efetividade do direito dos povos indígenas à educação, já que se relaciona diretamente com o direito à participação dos povos interessados nas políticas públicas e ao dever de transferir a responsabilidade pela educação às comunidades interessadas. A existência de um corpo docente preparado para ministrar aulas atento ao equilíbrio entre os conteúdos que contribuem para a participação da sociedade nacional e, ao mesmo tempo, a reprodução cultural - reafirmando ou redefinindo os objetivos internos de cada comunidade ou etnia corresponde, na realidade, à própria possibilidade de optar pelo futuro e inserção digna na sociedade, respeitado, dessa forma, seu direito à própria cultura.

Essa luta para uma educação escolar indígena de qualidade faz parte, portanto, da luta mais ampla dos povos indígenas, vai muito além dos sistemas de educação, essa luta perpassa pela necessidade de garantia dos territórios, da promoção da cultura materna, da cidadania, da saúde e da sustentabilidade .Estes desafios coletivos dos povos indígenas são também desafios da Educação Escolar indígena. A Educação Escolar indígena seria então um mecanismo concreto para que as comunidades indígenas pudessem ter soluções para tais problemas, no caso especifico sobre a formação escolar (básica) e universitária é necessária para que se possa ter um conhecimento mais amplo e concreto além da formação específica da importância da cultura e da diversidade indígena, ter conhecimentos sobre seus direitos legais e assim poderiam reivindicar seus direitos como cidadãos indígenas Brasileiros.

\section{Inclusão social e cultural nas escolas indígenas}

A escola para os povos indígenas surgiu de uma forma negativa, logo de início ela surge apenas como uma ação evangelizadora da Igreja, e tinha como principal objetivo o uso da mão de obra, o ensino era passado de uma forma que todos os conteúdos eram tidos como verdades absoluta e inquestionável, o aluno apenas teria que armazenar na memória os conteúdos e devolvê-los quando alguém o solicitasse.

A criação do SPI (Serviço de proteção ao Índio), em 1910, formula uma políticaindigenista menos desumana, 
baseada nos ideais positivistas do começo do século. Ainda seriam criadas várias organizações não-governamentais voltados para a defesa da causa indígena, e assim, com o surgimento das organizações governamentais e não-governamentais o movimento indígena começou a se organizar.

E finalmente esses povos de formas legais conseguem o seu direito por uma educação diferenciada intercultural e bilíngüe, a escola deveria ser intercultural e deveria promover o intercâmbio e a troca de conhecimentos, e assim foi proposto que a educação indígena fosse um espaço em que se possa pôr em contato diferentes concepções culturais, promovendo sínteses e alimentando o respeito pela diferença.Neste sentido o Referencial Curricular Nacional para Educação Indígena, diz que a escola indígena é intercultural:

Porque deve reconhecer e manter a diversidade cultural e lingüística; promover uma situação de comunicação entre experiências socioculturais, lingüísticas e históricas diferentes, não considerando uma cultura superior à outra; estimular o entendimento e o respeito entre seres humanos de identidades étnicas diferentes, ainda que se reconheça que tais relações vêm ocorrendo historicamente em contextos de desigualdade social e política (MEC, 2005, p. 24).

Os povos indígenas cada vez mais vêm se mostrando conscientes sobre os direitos que possuem, essa comunidade luta por uma educação que não os transforme por inteiro, mas, que deixem também a sua essência indígena, principalmente a sua cultura. A escola indígena deve contar com um currículo adequado a clientela que atende. $O$ conteúdo no caso a ser ministrado na escola segundo Brito, seria:

Deve estar voltado para a discussão da situação indígena, deacordo com a função a ser assumida pela educação para o índio.Isto inclui também o uso de elementos da cultura tradicional naescola, como os mitos, por exemplo. As proposições convergempara a utilização destes relatos como elemento motivador dentro da escola. [...] Os mitos podem ser utilizados para motivar a aprendizagem escolar, embora a escola não deva substituir os espaços próprios da tradição oral. (BRITO, 2004, p. 113).

São muitas as necessidades desses povos, e a cada dia essa comunidade vem buscando o seu direito a uma Educação Escolar Indígena, caracterizada pela afirmação das identidades étnicas, pela recuperação das memórias históricas, pela valorização das línguas e conhecimentos dos povos indígenas, tudo alcançado até hoje foi uma conquista das lutas empreendidas pelos povos indígenas e seus aliados, e um importante passo em direção da democratização das relações sociais no país.

\section{Perceptivas do avanços e processo ensino e aprendizagem}

Os avanços na educação escolar indígena nos últimos anos podem ser classificados em três categorias, sendo elas: legal, político e pedagógico. O reconhecimento político e jurídico da educação escolar específica e diferenciada como direito coletivo que orientou a expansão do atendimento da oferta escolar no âmbito do sistema nacional de ensino, superando a visão assistencialista e paternalista do indigeníssimo colonial e; o reconhecimento da importância do protagonismo indígena em todo o processo educativo das comunidades indígenas com o surgimento de professores e técnicos indígenas no magistério e gestão de suas escolas.

No campo da educação escolar indígena, o reconhecimento sociocultural e étnico possibilitou, entre outras conquistas, o uso, a promoção e a valorização da língua materna e dos processos próprios de ensino-aprendizagem no âmbito das escolas das aldeias, cuja base legal está explícita na Constituição Federal de 1988:

O ensino fundamental será ministrado em língua portuguesa, assegurada às comunidades indígenas também a utilização de suas línguas maternas e processos próprios de aprendizagem (Artigo 210, Inciso 2).

Outros dispositivos legais tais como a Lei de Diretrizes e Bases da Educação Nacional (LDB) de 1996, a Convenção 169 da Organização Internacional do Trabalho (OIT) adotada pelo Brasil em 2004 e do Plano Nacional de Educação reafirmam o reconhecimento dos direitos de autonomia político-pedagógica das escolas indígenas na definição e implementação de processos educativos inerentes aos sistemas sócio educativos de cada povo.

O desafio enfrentado pela atual escola indígena é o dilema da comunicação e da convivência intercultural (CANDAU, 2006) que se tornou sua principal estratégia político-pedagógica. Trata-se do dilema de atender ao mesmo tempo as demandas pelo resgate, manutenção e valorização dos conhecimentos, das culturas, das tradições e dos valores tradicionais próprios dos povos indígenas e o acesso aos conhecimentos, às técnicas e aos valores da sociedade envolvente.

Os desafios que os povos indígenas enfrentam na atualidade exigem dos professores indígenas uma postura e um trabalho adequado e responsável. Devem estar comprometidos em desenvolver o processo de ensino-aprendizagem não como únicos detentores de conhecimentos, mas como articuladores, facilitadores, intervindo, orientando, problematizando, sem desconsiderar a atitude da curiosidade dos diversos alunos para os novos conhecimentos. A escola indígena deve ser espaço de pesquisa e de produção de conhecimentos e de reflexão crítica por parte de todos os que participam dela. (RCNEI, 1998, p. 41)

A conquista dos direitos legais é em sim mesma relevante, pois, é a partir destas leis que os povos indígenas ganham força e legalidade para cobrar dos governos sua aplicação. Além disso, os povos indígenas ganham amparo político-jurídico em suas iniciativas.

As possibilidades trazidas pelas ideias inovadoras da escola indígena própria animaram os povos indígenas na luta por ela. Em resposta a essa demanda, os sistemas de ensino também em diferentes níveis, formas e compromissos, passaram a se organizar para ampliar o atendimento e melhorar a qualidade do ensino, segundo 
os princípios da nova escola indígena específica, diferenciada, bilíngüe e própria. Para o RCNEI (1998):

A escola não deve ser vista como o único lugar de aprendizado. Também a comunidade possui sua sabedoria para ser comunicada, transmitida e distribuída por seus membros; são valores e mecanismos da educação tradicional dos povos indígenas. Essas formas de educação tradicional podem e devem contribuir na formação de uma política e prática educacionais adequadas, capazes de atender aos anseios, interesses e necessidades diárias da realidade atual.

Outro avanço importante é o novo papel das comunidades indígenas, fortalecidas com o crescente protagonismo indígena na condução local da gestão e do processo pedagógico das escolas. Mas, mesmo diante de avanços conceituais, políticos, pedagógicos, gerenciais e financeiros, as escolas indígenas ainda enfrentam grandes desafios e problemas oriundos dos limites do modelo político-administrativo das políticas públicas adotados pelos governos e pelo Estado. Tudo indica que o principal desafio para os próximos anos no campo das políticas públicas de educação escolar indígena, assim como de outros direitos indígenas, é fazer valer na prática os direitos conquistados.

A implementação das leis e normas estabelecidas, se tornam, portanto, a principal possibilidade de garantir uma educação escolar de qualidade para os povos indígenas, de acordo com seus anseios e planos de vida. Mas esta possibilidade precisa ser construída no dia-a-dia da escola.

\section{Conquista alcançadas e lutas constantes para o uso da língua materna e o ensino bilingue}

Quando os indígenas começaram a compreender e a dominar a língua portuguesa, viram que somente através dela é que sería possível revindicar seus direitos, então a utilizaram como ferramenta para que fossem os poucos introduzidos como cidadãos de direitos, cada vez mais obtendo os conhecimentos dos não-índios para utilizarem como recurso na conquista de seus direitos perante ao poder legislativo. Visam na aquisição de conhecimentos uma porta para elaboração de políticas linguísticas em um país que se perpetuou por longas datas a negação da língua indígena. (ANFOSO, 2014)

Acreditava-se que ao impor a língua teriam o domínio absoluto sobre o território e sobre as mentes dos indígenas, entre todas essas lutas por igualdade de direitos haviam todo um interesse político, territorial e cultural que também estão ligados à perda cultural, uma vez que a expressão é uma forma de poder e a busca por maior representatividade na sociedade contribui para o desaparecimento da língua minoritária. Quanto mais se estabelece contato, os indígenas veem o português como uma forma de conquistar espaço, uma ferramenta de poder.

Com a promulgação da Constituição de 1988, algumas coisas se modificam, pela primeira vez no sistema legislativo brasileiro, os indígenas têm direito ao uso de suas línguas maternas e de seus processos próprios de aprendizagem, ou seja, o índio passa a ter direito de ser ele mesmo, com suas expressões socioculturais, língua, rituais, tradições e forma própria de organização social. E em seu parágrafo $2^{\circ}$, no artigo 210 , diz que "o ensino fundamental será ministrado em língua portuguesa, assegurada às comunidades indígenas também a utilização de suas línguas maternas e processos próprios de aprendizagem" (BRASIL, 1988). E com o avanço do tempo, na LDB 9.394/96 no capítulo 32, reafirma o que foi estabelecido pela Constituição de 88, e no seu Art. 78 da Seção III - Do Ensino Fundamental da LDB 9394/96 estão relacionados os objetivos da educação escolar bilíngue e intercultural voltada aos povos indígenas, quais sejam: "I - proporcionar aos índios, suas comunidades e povos, a recuperação de suas memórias históricas; a reafirmação de suas identidades étnicas; a valorização de suas línguas e ciências;” LDB (1996).

Atualmente está registrado o direito ao ensino também da língua materna, mas nós sabemos que nem tudo que está na lei é posto em prática na Lei de Diretrizes e Bases da Educação Nacional, Lei n9394/1996 o artigo 78 determina que o Sistema de Ensino da União desenvolva sistemas integrados de ensino e pesquisa para a oferta de educação escolar bilíngue e intercultural aos povos indígenas, respaldando, implicitamente a criação de um subsistema de ensino voltado exclusivamente para a educação indígena, que poderá estruturar-se de forma completamente diferenciada dos sistemas de ensino dirigidos às populações não-índias. Assegurando que a educação indígena ofereça, além dos principais aspectos da cultura ocidental, ou seja, da cultura do não-índio, um ensino que valorize os conhecimentos tradicionais dos povos indígenas, suas práticas culturais e suas línguas.

Mas o que realmente acontece na pratica é que não há material, formação, estrutura para o desenvolvimento de tais direitos. Na aldeia dos Parintintin que são o público alvo neste trabalho, nem um dos professores que ministram aulas na aldeia é indígena, somente Dona Claudete que nas horas vagas oferece uma pequena aula na língua materna dos mesmos, mas não possui formação para desenvolvimento de tal atividade, uma aula de cunho improvisatório, somente o uso da oralidade, sem proporcionar uma verdadeira educação bilíngue.

Para uma melhor e eficaz aprendizagem é preciso que se atenda a está comunidade em todos os aspectos necessários para que seja possível reerguer a língua materna dos Parintintin, eles estão tentando a sua maneira, mas falta um olhar do poder público para que se possa melhorar o ensino bilíngue nesta aldeia.

\section{Considerações finais}

Diante da trajetória e desafios enfrentados e que ainda serão vencidos, a experiência de poder conhecer o ensino em uma aldeia indígena foi de suma relevância para a minha formação enquanto futura educadora. A aldeia da Pupunha está muito próxima ao contato com os humaitaenses, mas mesmo assim, a situação do ensino é de um caráter precário, falta estrutura, recursos didático-pedagógicos, professores indígenas formados e habilitados a desenvolver tanto a língua materna como o despertar da cultura. Na aldeia há professores não indígenas dispostos a atuarem como verdadeiros 
educadores, colocando-se a deposição para a conquista de uma educação de qualidade, mas mão bilíngue, pois os mesmos não possuem formação e tão pouco fazem parte da etnia Parintintin, conhecem a cultura da etnia superficialmente, como poderão passar valores, crenças, e o ensino da língua materna se não estão habilitados a desenvolver tal ação. É uma questão a ser repensada, e questionada não só por nós ou pelos Parintintin, mas principalmente pelo poder público.

No que diz respeito ao ensino da língua materna, Dona Claudete está disposta e determinada a não permitir que seu povo perda seus costumes e muitos menos sua identidade. Afinal, a solução está no protagonismo dos próprios indígenas, eles próprios estão trabalhando para que haja a preservação da sua cultura, a sobrevivência da cultura também depende da atuação dos próprios indígenas com um trabalho de valorização transmitido as novas gerações, e que a língua que estão aprendendo não fique somente circulando nas paredes da escola, que eles possam colocar em prática no seu cotidiano e assim resgatar e estabelecer a cultura Parintintin.

\section{Referências}

Afonso, M, A. V. (2014). Políticas linguísticas para os povos indígenas no brasil. João Pessoa/Paraíba.

Brasil, Lei de Diretrizes e Bases da Educação Brasileira-LDB (1988). Lei $n^{\circ}$ 9394/1996. BRASIL, Constituição da República do Brasil. Art. 26, § $4^{\circ}$-Seção I. Cap II.

Brasil (1988). Constituição da República Federativa do Brasil. Promulgada em 5 de outubro de 1988. Brasília: Câmara dos Deputados, Coordenação de Publicação, 2001.

Brasil. Ministério da Educação (2002). Referenciais para a formação de professores indígenas/Secretaria de Educação Fundamental. Brasília: MEC; SEF.

Brasil (1998). Referencial curricular nacional para as escolas indígenas/Ministério da Educação e do Desporto, Secretaria de Educação Fundamental. Brasília: MEC/SEF.

Brito, S. H. A. de (2004). Educação e Diversidade em questão: examinando os projetos alternativos de escolas para o índio nos anos 70. In: CAETANO, C. V.; BRITO, S.A. de (Orgs). Educação e diversidade cultural. Campo Grande: UNIDER.

Candau, V. (org.) (2006). Educação intercultural e cotidiano escolar. Rio de Janeiro: 7 Letras.

Maturana, H.; Rezepeka, N. S. (2002). Formação humana e capacitação. Petrópolis: Vozes.

Ministério da Educação (2005). Parâmetros Curriculares Nacionais. SECAD/DEDOC/ CGEEI. Brasília: MEC,

\section{Agradecimentos}

Ao Programa de Pós-Graduação em Ensino de Ciencias e Humanidades da Universidade Federal do Amazonas. 